\title{
APLICAÇÃ̃ DE SIMULAÇÃo NUMÉRICA E ANÁLISE DE SENSIBILIDADE PARA TOMADA DE DECISÃO NA EXPLORAÇÃO DE RESERVATÓRIOS DE PETRÓLEO PRODUZIDOS POR MALHAS FIVE-SPOT DE INJEÇÃO DE ÁGUA
}

\author{
Elísio Fernandes de Almeida Quintino \\ Universidade Federal do Rio de Janeiro \\ elisiofaq@poli.ufrj.br \\ Luis Henrique Costa Neto \\ Universidade Federal do Rio de Janeiro \\ lhcneto@poli.ufrj.br
}

\begin{abstract}
Resumo
O presente trabalho tem como objetivo propor um método de análise econômica e tomada de decisão para problemas de injeção de água em reservatórios de petróleo. É tratado o problema específico da escolha da dimensão ótima de uma malha five-spot , a fim de maximizar o valor presente líquido de um projeto de exploração de reservatório com injeção de água. É utilizada uma análise geométrica pautada na física do escoamento em meio poroso com o objetivo de possibilitar a realização de múltiplas simulações a menor custo computacional. A questão é formulada como um problema de otimização com restrição e, a partir dos resultados, é feita uma análise de viabilidade econômica e análise de sensibilidade, com o objetivo de sustentar a tomada de decisão.

$\begin{array}{llll}\text { Palavras-Chaves: } & \begin{array}{l}\text { Reservatórios de petróleo; } \\ \text { Otimização com restrição; } \\ \text { decisão. }\end{array} & \begin{array}{l}\text { Injeção de água; } \\ \text { Análise de sensibilidade; }\end{array} & \text { Five-spot; } \\ & \text { Tomada de }\end{array}$
decisão.
\end{abstract}

\begin{abstract}
This work proposes a method for analyzing the decision-making of problems of water injection into oil reservoirs. We treat the specific problem of dimension optimization for a five-spot grid to maximize the net present value of a project of oil extraction with water injection. We use a geometric approach based on the physics of flow in a porous media aiming to make the computations more cost-efficient. The problem is posed as an optimization one with restrictions and the output of the simulation is used to analyze the economic viability of the project, and a sensitivity analysis is made to guide decision- making. Keywords: Petroleum reservoirs; Water injection; Five-spot; Optimization with constraints; Sensitivity analysis; Decision-making
\end{abstract}




\section{INTRODUÇÃO}

A injeção de água é um método de recuperação de óleo amplamente utilizado na indústria do petróleo. Consiste em injetar água a partir de poços injetores com o objetivo de deslocar o óleo do reservatório em direção aos poços produtores, aumentando assim o fator de recuperação do reservatório. Esse método é considerado um método de recuperação secundária, ou seja, um método a princípio utilizado para recuperar óleo que não pôde ser produzido com a energia inicial presente no reservatório. Entretanto, o sucesso da injeção de água vem permitindo que seu planejamento e, por vezes, uso sejam iniciados logo no princípio da vida produtiva do campo [1].

Um modelo clássico de organização de poços injetores e produtores é o padrão five-spot, onde uma célula unitária formada por poços injetores nos vértices de um quadrado e um poço produtor no meio do quadrado se repete na área do reservatório, formando uma malha de injeção e produção. Dada sua ampla utilização na indústria, o estudo do modelo fivespot é extremamente importante para o bom planejamento da exploração de campos de petróleo e para a otimização da produção.

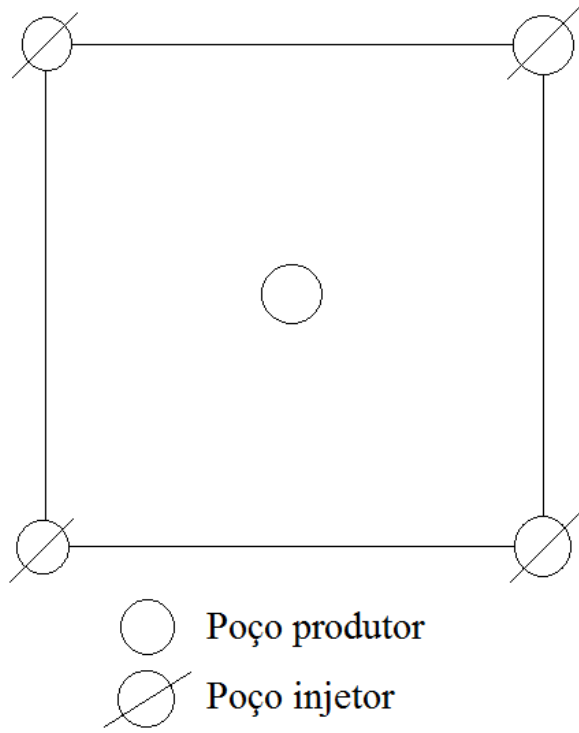

Figura 1 - célula unitária five-spot com produtor no centro

Dito isto, uma questão pode ser posta em relação à exploração de um campo com a utilização de uma malha five-spot de injeção e produção: qual o número ótimo de células unitárias para determinada área explorada? Isso quer dizer, em quantas células de 4 injetores e 1 produtor eu devo dividir a minha área, de modo a otimizar meu lucro com a exploração do campo? Será verificado adiante que a questão é pertinente, visto que um número muito pequeno de células implica um número pequeno de poços produtores, logo a produção diária é pequena e isso implica um valor presente líquido também pequeno. Por outro lado, com um número muito grande de células, e consequentemente de poços, o custo total relacionado à instalação de poços supera a receita gerada pelo aumento da produção diária, de modo que o lucro final diminui. Sendo assim, é esperado que exista uma escolha ótima, dependente dos dados do problema, que maximize o lucro total do projeto e não seja uma escolha trivial, ou seja, não seja nem a escolha de uma única célula nem de infinitas. Essa existência será verificada mediante um estudo numérico. Além disso, restrições técnicas e financeiras existem para uma empresa de exploração de petróleo, logo suas representantes mais imediatas são impostas ao problema, a saber, o tempo de exploração e o cut de água, ou fração de água produzida, aceitável para a empresa exploradora, visto que essas duas restrições são de grande importância na exploração de um campo de petróleo. 
A solução do problema será realizada por meio de simulações numéricas, de onde as informações do valor presente líquido da produção de óleo serão obtidas e, combinadas ao custo total resultado da instalação de poços no projeto, indicarão qual a melhor escolha a ser feita em relação à malha five-spot. Logo depois, uma análise de sensibilidade será aplicada, a fim de observar a influência da variação dos parâmetros do problema para o lucro total obtido e, portanto, para a tomada de decisão. Para o estudo, algumas simplificações serão admitidas, entendendo que a solução do modelo simples, assim como as estratégias empregadas no processo, pode servir de base para estudos mais complexos e realistas.

Embora a realização de múltiplas simulações para o reservatório inteiro, cada uma com sua malha de injeção, pudesse ser uma forma de gerar e comparar valores de lucro final, de modo a identificar a configuração de lucro máximo, é utilizada aqui uma estratégia que leva em consideração um argumento de simetria bem conhecido na engenharia do petróleo, a fim de diminuir o custo computacional envolvido nas simulações. Esse argumento será o primeiro tópico apresentado nesse artigo.

\section{O ARGUMENTO DE SIMETRIA}

Dado um reservatório horizontal, infinito, homogêneo e isotrópico, e dois poços a uma distância $h$ entre eles, ambos produzindo ou injetando à mesma vazão, sabe-se que nenhuma linha de fluxo de fluidos pode cruzar a reta perpendicular à distância entre os poços e equidistante entre eles. Ou seja, entre dois poços de mesma vazão e distantes $h$ entre si, existe uma reta que passa entre esses poços, dista $h / 2$ de cada um deles e que funciona fisicamente como uma barreira ao fluxo, como um bordo selado. Como consequência, as partições do reservatório de cada lado da reta podem ser tratadas separadamente se for imposta a condição de contorno de fluxo nulo através dessa reta [1].
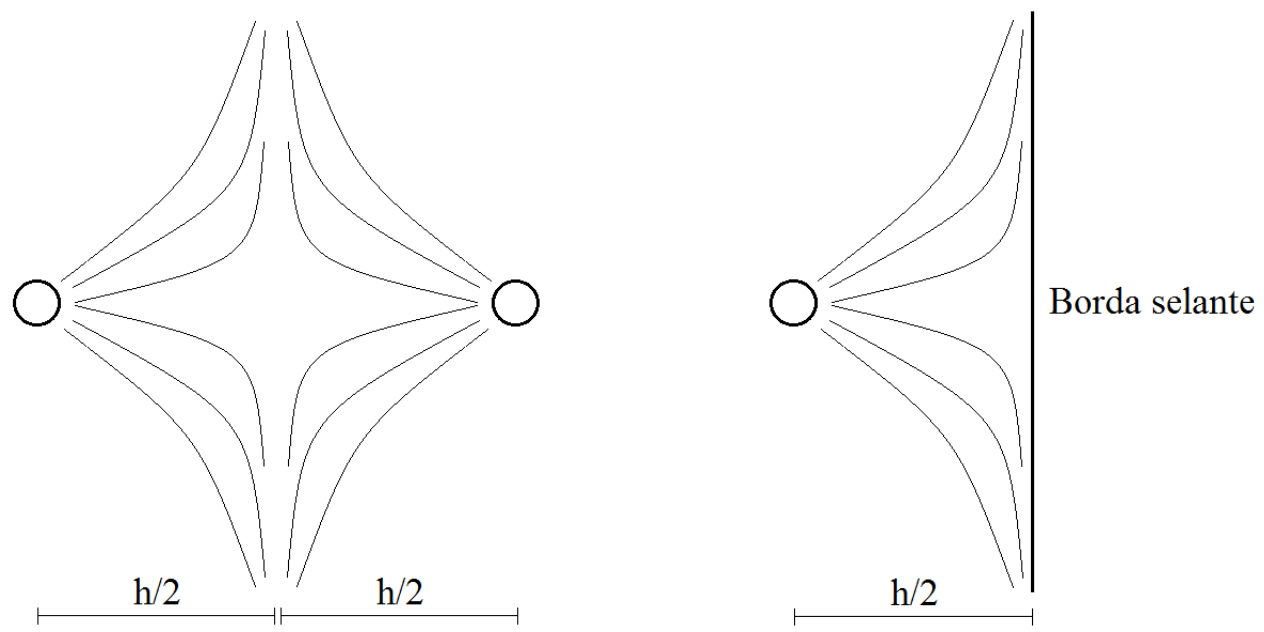

Figura 2, esquerda - dois poços a uma mesma vazão e distância $\mathrm{h}$.

Figura 3, direita - um poço a uma distância $\mathrm{h} / 2$ de uma borda selante.

É possível estender esse raciocínio para um conjunto de células unitárias fivespot. Dado um reservatório infinito com uma malha de injetores e produtores perfeitamente simétrica, onde os poços apresentam o mesmo valor absoluto de vazão, sendo esse valor prescrito e constante, é possível modelar o comportamento de qualquer ponto no reservatório apenas modelando uma única célula unitária five-spot, e estabelecendo que essa célula se repete infinitamente em todas as direções. Para isso, é importante observar que os poços injetores produzem vazão simetricamente para quatro células adjacentes, se considerarmos que eles estão localizados nos vértices das células. Enquanto isso, os poços produtores, por estarem localizados nos centros das células, produzem vazão apenas para a célula onde se encontram. Dessa forma, com essa convenção de geometria, deve-se modelar a célula five- 
spot com cada um dos 4 injetores injetando a uma vazão correspondente a $1 / 4$ da vazão de produção do poço produtor. Se a convenção oposta fosse tomada, onde os vértices do quadrado abrigam os poços produtores, raciocínio análogo deveria ser realizado, fazendo com que cada produtor produzisse à vazão equivalente a 1/4 da vazão de injeção.
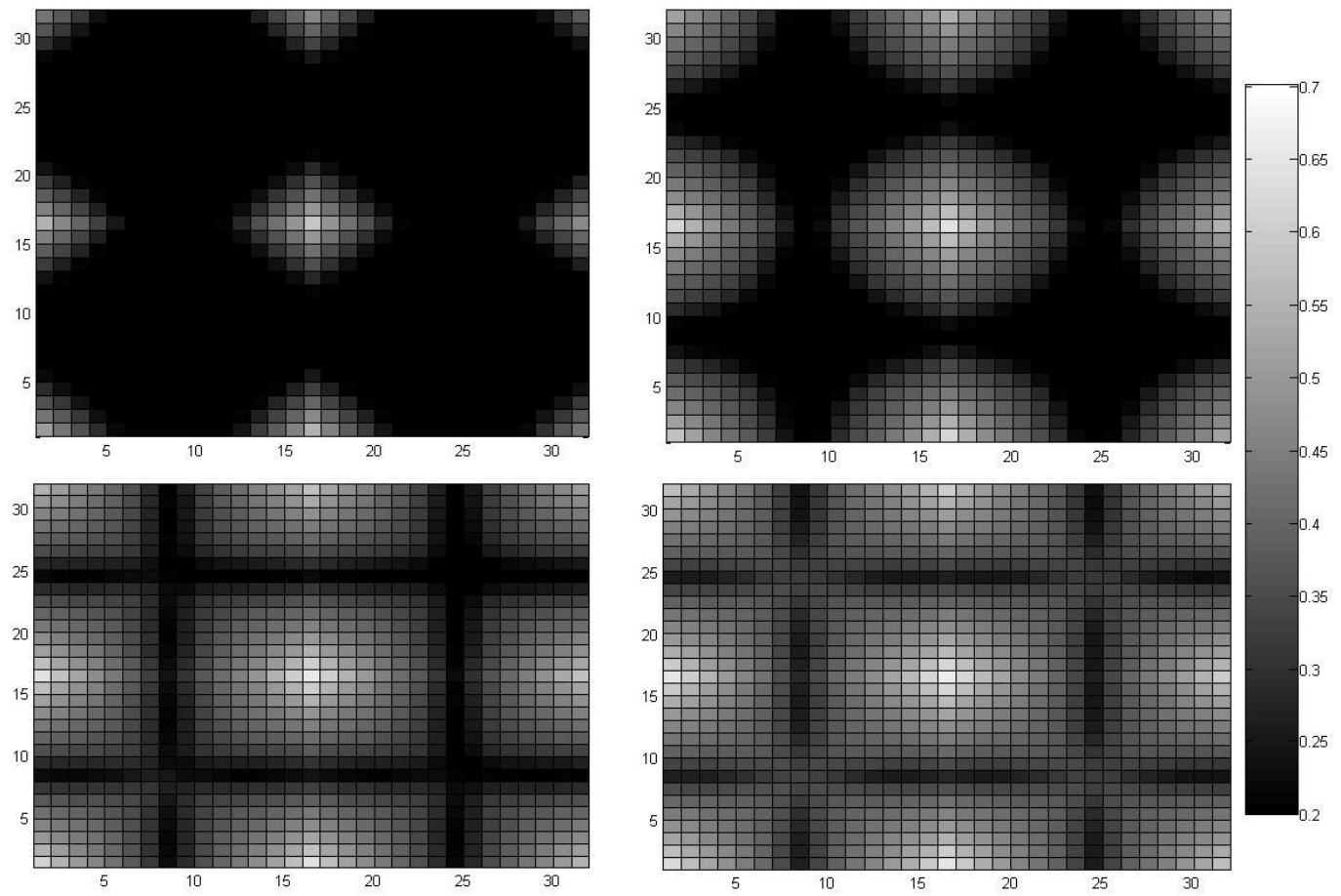

Figura 4 - reservatório explorado com 4 células five-spot sendo simulado sem uso da estratégia geométrica, com a impressão de quatro momentos de tempo. Em preto, a saturação de água é mínima e em branco, máxima.
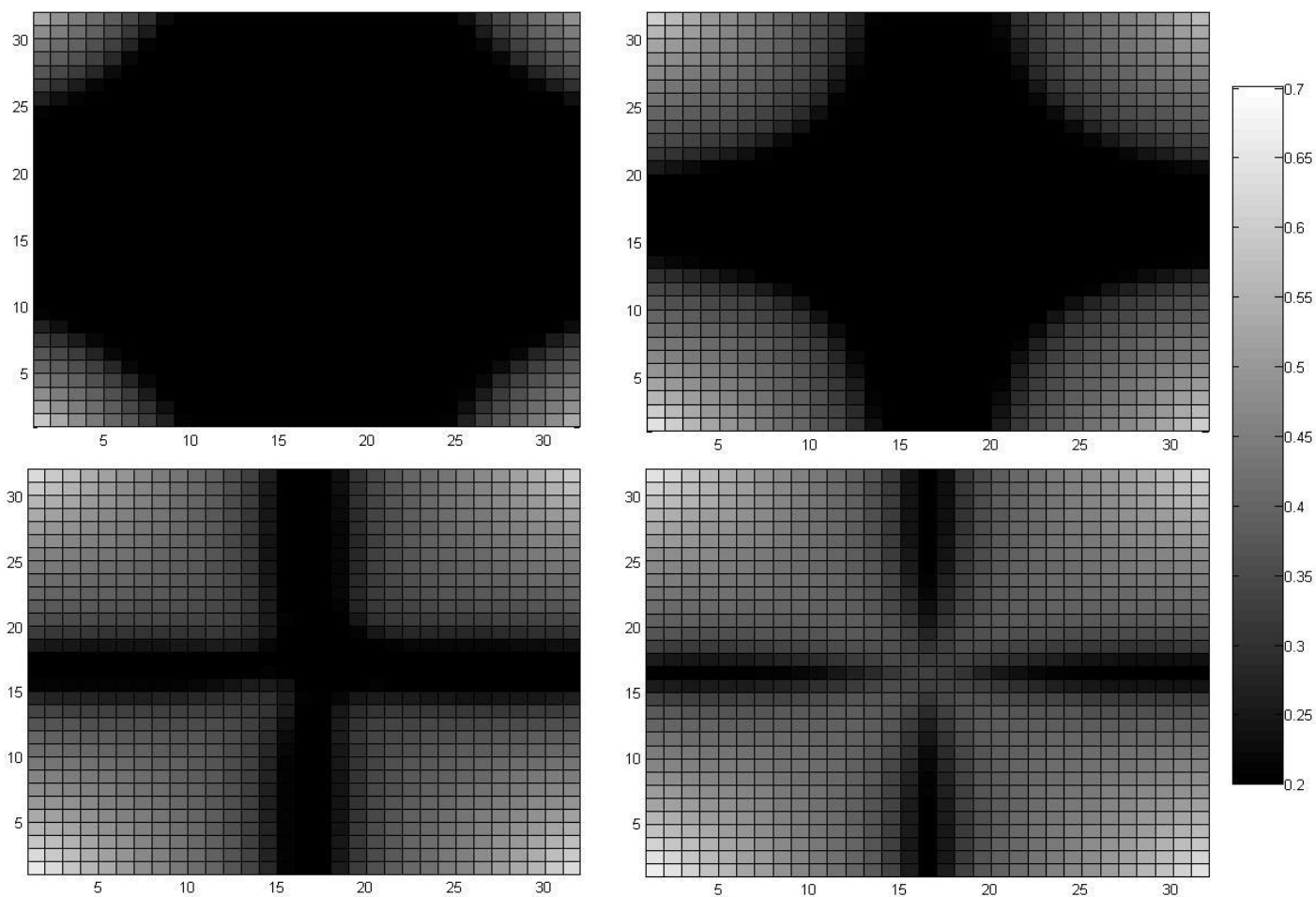

Figura 5 - área correspondente a uma única célula five-spot do reservatório anterior sendo simulada como um reservatório por si só, com contorno externo selado. Numericamente, verifica-se o que essa comparação sugere: o mesmo efeito é gerado simulando-se o reservatório inteiro ou cada uma de suas células five-spot separadamente. 
Se quisermos substituir o reservatório infinito por um reservatório finito com fronteiras seladas, ou seja, de fluxo nulo através das bordas, podemos fazê-lo de maneira imediata. Para isso, basta tomar qualquer contorno que passe pela fronteira de células unitárias five-spot e identifica-lo como fronteira selada do reservatório. Isso é possível porque, como visto anteriormente, é matematicamente equivalente modelar uma fronteira de reservatório de fluxo nulo e a linha imaginária que separa células five-spot adjacentes. Assim, a fronteira externa do reservatório passa a ser nada mais do que um conjunto de limites imaginários de células five-spot que possam ser interligados.

As restrições para que esse procedimento forneça resultado exato são fortes, mas tal aproximação permite que uma rápida e ágil primeira impressão seja fornecida a respeito do problema, permitindo assim que otimizações mais robustas e custosas sejam realizadas em um domínio mais restrito e, portanto, tempo e custo computacional sejam economizados.

A primeira restrição é que se assume que as bordas do reservatório, quadrado, coincidem com as bordas de células unitárias five-spot, o que pode ser bastante distante da realidade. Além disso, os poços injetores nas bordas do reservatório devem ter vazão de injeção proporcional ao número de células para as quais injetam. Isso decorre do fato que, já que, em nosso modelo de reservatório infinito, escolhemos colocar os poços injetores nos vértices das células, cada injetor contribui com 1/4 de sua vazão de injeção para cada célula adjacente, fazendo com que injetores que estejam localizados em bordos do reservatório só produzam os efeitos desejados na física do problema se forem modelados de forma a injetarem menos água, proporcionalmente ao número de células existentes ao seu redor.

Esse argumento de simetria permite modelar o reservatório de uma forma que o problema, embora simplificado, pode ser resolvido de maneira mais eficiente. Dividindo o reservatório em diversas células five-spot, ao invés de realizar simulações com todo o reservatório e diferentes configurações de poços, é possível simular apenas uma célula fivespot e depois multiplicar a produção de fluidos pelo número de células. Esse procedimento é mais rápido computacionalmente e requer menor armazenamento de dados, já que armazena apenas uma vez informações que se repetiriam para várias células.

Para reservatórios anisotrópicos, heterogêneos, de outras geometrias, com poços injetando e produzindo a diferentes valores de vazão, os resultados da estratégia acima serão tão próximos da realidade quanto menores forem os desvios em relação às hipóteses de isotropia, homogeneidade e único valor de vazões. Entretanto, mesmo para reservatórios em condições afastadas das aqui requeridas, a presente análise pode auxiliar no processo de tomada de decisões como uma primeira ferramenta de avaliação, ou como a base para o desenvolvimento de ferramentas mais adequadas à realidade do problema.

\section{FORMULAÇÃO DO PROBLEMA DE OTIMIZAÇÃO}

O problema da escolha da densidade da malha five-spot, ou seja, da quantidade de células unitárias five-spot nas quais a área será dividida, pode ser modelado como um problema de otimização com restrição. De maneira sucinta, objetiva-se maximizar o lucro total, função do número de partições do reservatório, com as restrições de que a produção de água no poço produtor não pode ser maior do que determinado valor e existe um tempo máximo para a operação do campo, ou seja, a produção cessa descontinuamente nesse instante de tempo.

No modelo estudado, o lucro total é calculado pela receita gerada pela produção de óleo menos os custos com a implantação de poços. Para a receita do óleo, é utilizado um modelo de decaimento exponencial da receita unitária com o tempo, o que possibilita que a receita total seja trazida para valor presente. Os custos com poços são dados já em valor presente, sendo considerado que todos os poços são construídos no tempo zero. O modelo formado por essas hipóteses é bastante simples, mas já permite revelar o comportamento interessante e não monótono da função a ser maximizada, justificando a proposta do 
problema. Receitas e custos podem ser adicionados à função objetivo de modo a tornar o modelo mais próximo da realidade.

Como já comentado, duas restrições são impostas ao problema. A primeira delas é relativa ao cut de água, ou fração da vazão total de fluido produzido constituída por água. Essa fração não pode exceder um limite pré-determinado, o que simboliza em termos práticos as limitações técnicas ou de atratividade da empresa para o tratamento da corrente óleo-água produzida com porcentagem suficientemente alta de água. Como o cut de água no poço produtor é uma função monótona crescente, essa condição é implementada na estratégia de solução do problema simplesmente executando a interrupção da simulação quando a fração de água no poço produtor alcança o valor estipulado.

A segunda restrição impõe uma limitação no tempo de exploração do reservatório, e significa na prática, por exemplo, o tempo de contrato de exploração entre a empresa e o agente administrador do campo. Como o tempo também cresce monotonamente, essa restrição é traduzida pelo fim da simulação se o tempo limite for atingido.

\subsection{O Problema em Termos Matemáticos}

É importante formalizar as noções da seção anterior. Em primeiro lugar, dada uma malha five-spot com célula unitária quadrada de lado $a$, refinar essa malha significa, progressivamente, dividir cada célula da malha anterior em 4 quadrados de lado $a / 2$. Dessa forma, se meu reservatório inteiro é quadrado e tem lado $a$, minha otimização será realizada escolhendo dentre os argumentos $\left\{a, a / 2, a / 4, a / 8, \ldots, a / 2^{n}, \ldots\right\}$ aquele que implica a função lucro total atingir seu maior valor.

Por sua vez, a função lucro total, que é a função objetivo a ser maximizada, é composta da seguinte forma:

-Seja $P(t)$ a função receita unitária do óleo em função do tempo, por exemplo em dólares por barril, que representa o desconto na receita unitária de determinado instante de tempo quando a análise de valor presente é aplicada.

-Seja INJ o custo unitário de um poço injetor, e $P R O$ o custo unitário de um poço produtor, ambos valores constantes conhecidos. Além disso, considere ninj(part) e npro(part) o número de poços injetores e produtores, respectivamente, como função do número de partições do reservatório. A relação dessas duas últimas quantidades com o número de partições do reservatório inteiro, part, será explicitada mais adiante.

-Seja $F o(t, p a r t)$ a função fração da produção total de fluido no poço produtor, em volume, equivalente ao óleo. Note-se que a função $F o$ varia entre 0 e 1 . Como se admitem vazões prescritas, e sendo $Q$ a vazão prescrita no produtor, tem-se que a função vazão de óleo no produtor, em função do tempo e da dimensão da célula unitária five-spot, é $Q^{*} F o(t$,part).

-Seja Tmax o tempo $t$ máximo permitido, e Cutmax o maior cut de água no produtor permitido, nos termos já apresentados anteriormente.

Então, podemos escrever da seguinte forma o problema de otimização aqui tratado:

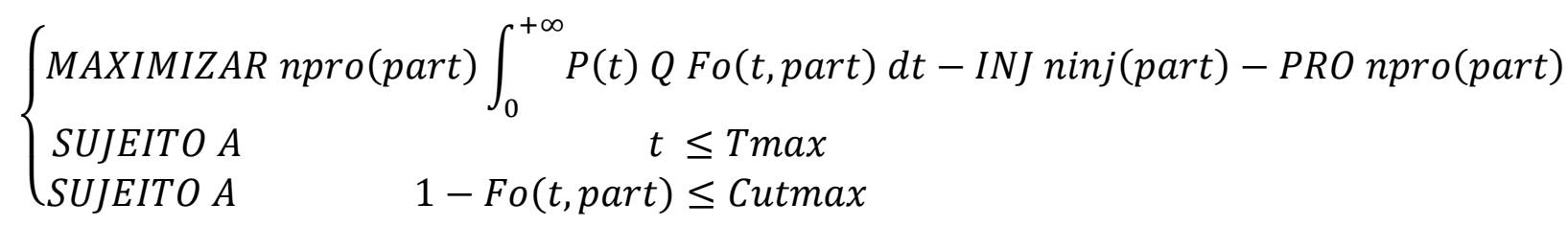

A integral presente na função objetivo representa o somatório das parcelas de receitas nos respectivos instantes de tempo ponderadas pela função de desconto, de modo que seu resultado é o valor presente dessa receita, ainda em função do particionamento. Pode-se implicitar a restrição do tempo na formulação da função objetivo, de modo que o problema se torna: 


$$
\left\{\begin{array}{l}
\text { MAXIMIZAR npro(part }) \int_{0}^{\text {Tmax }} P(t) Q F o(t, \text { part }) d t-I N J \text { ninj }(\text { part })-P R O \text { npro }(\text { part }) \\
\text { SUJEITO A } A \text { C } 1-F o(t, \text { part }) \leq \text { Cutmax }
\end{array}\right.
$$

O problema acima, a ser resolvido para a variável part, que representa o número de células unitárias escolhido para dividir o domínio do reservatório, mesmo com todas as simplificações apresentadas nas seções anteriores, já não pode ser resolvido analiticamente, já de início devido ao fato de que a função $F o$ é representada por um simulador numérico, logo não possui derivadas analíticas.

\subsection{O Termo de Custos no Lucro Total}

A parte de custos envolvida na função objetivo vem dos gastos com poços produtores e injetores. Esses gastos são função dos custos unitários dos poços, valores constantes dados, e de sua quantidade, e esta última depende diretamente do número de partições realizadas no reservatório.

Em um reservatório quadrado, partindo de uma malha constituída por uma única célula unitária quadrada, onde estão instalados 4 injetores e 1 produtor, pode-se dividir essa malha em 4 malhas menores de mesmas dimensões, reposicionando em cada vértice um poço injetor e em cada centro de célula um poço produtor. Repetindo esse procedimento um número indefinido de vezes, as seguintes relações recursivas são válidas para o número de poços em malhas mais densas:

$$
\begin{aligned}
& \operatorname{ninj}_{n+1}=\left(2 \sqrt{\operatorname{ninj}_{n}}-1\right)^{2} \\
& \operatorname{nprod}_{n+1}=4 \operatorname{nprod}_{n}
\end{aligned}
$$

Dessa forma, partindo de $\operatorname{nprod}_{0}=1$ e $\operatorname{ninj}_{0}=4$, o que corresponde ao número de poços produtores e injetores para uma única célula unitária no reservatório, o número de produtores e injetores, em função do número de células, varia da seguinte forma, que pode ser facilmente verificada:

$\begin{array}{llllll}\text { Número de células } & 1 & 4 & 16 & 64 & \ldots \\ \text { Número de produtores } & 1 & 4 & 16 & 64 & \ldots \\ \text { Número de injetores } & 4 & 9 & 25 & 81 & \ldots \\ \text { Número total de poços } & 5 & 13 & 41 & 145 & \ldots\end{array}$

\subsection{O Termo de Receitas no Lucro Total}

A receita gerada pela produção do óleo tem dois componentes em seu cálculo. O primeiro deles é o próprio simulador, que recebe uma série de parâmetros, como dimensões, campos de porosidade e permeabilidade, curvas de permeabilidades relativas e propriedades dos fluidos, e fornece os campos de saturações e pressões em função do tempo e espaço e as curvas de produção de fluidos nos poços produtores. Em termos das variáveis que participam ativamente do problema de otimização aqui posto, o simulador é representado pela função produção de óleo no poço produtor, ou seja, $Q F o(t, p a r t)$, dependente do tempo e do tamanho da célula five-spot utilizada, este último implicado pelo número de partições do reservatório.

O segundo componente é a receita unitária da produção de óleo por poço produtor, ou seja, a receita por barril produzido, como função do tempo e cuja forma depende da receita no tempo $t=0$ e da taxa de desconto nominal anual, ambos parâmetros conhecidos. 
Essa função, em nosso estudo, tem comportamento exponencial negativo, podendo ser escrita como:

$$
P(t)=P(t=0) e^{-r t}
$$

onde $r$ é a taxa de desconto nominal anual e $t$ é o tempo decorrido em anos.

A receita total depende do número de partições do reservatório de duas maneiras. Primeiro, o número de poços produtores depende do número de partições, já que existe um poço produtor para cada célula unitária. Logo, a receita relativa a um poço deve ser multiplicada pelo número de células. Depois, quanto menor for a célula five-spot, mais rápido a produção atingirá o nível proibitivo do $c u t$ de água, visto que poços produtores e injetores estarão mais próximos um do outro, logo não só a quantidade de óleo produzido cai mais rápido, como também o cut de água máximo é atingido mais cedo e a produção cessa. $\mathrm{O}$ balanço entre esses efeitos está no cerne da escolha do número ótimo de partições.

\section{APLICAÇÃO DO MÉTODO}

Nesta seção será aplicado o método descrito a um caso exemplo. São admitidas para a física do problema aqui tratado as hipóteses de escoamento bidimensional horizontal, bifásico óleo-água, imiscível e incompressível. A pressão capilar é desprezada e os efeitos do escoamento bifásico são traduzidos a partir de curvas de permeabilidades relativas como funções das saturações de fluidos, seguindo os modelos de Corey. O reservatório é quadrado, homogêneo e isotrópico. O simulador utilizado, elaborado pelos autores, utiliza um método IMPES para a simulação do escoamento no reservatório.

Considera-se que o reservatório possui dimensões de $4096 \mathrm{~m}$ por $4096 \mathrm{~m}$ e uma espessura média de $15 \mathrm{~m}$. A permeabilidade média vale $100 \mathrm{mD}$ e a porosidade média vale 0,25 . Os poços produtores possuem vazão de 2000 barris/dia, o que implica a vazão de 500 barris/dia para os injetores, quando representados em uma célula unitária. O tempo máximo de exploração do reservatório é de 20 anos e o cut máximo de água admitido é de $70 \%$. O preço de poços injetores é estipulado em US\$ 60 milhões e o custo dos produtores é de US\$ 40 milhões. A receita unitária com a produção de 1 barril de óleo é de US\$50,00 e a taxa de desconto para valor presente é de $15 \%$ ao ano.

A fim de estudar a função objetivo, foram rodadas simulações para células fivespot de dimensões laterais 4096 m, 2048 m, 1024 m, 512 m e 256 m, que indicam a divisão do reservatório em respectivamente 1, 4, 16, 64 e 256 células five-spot. Os resultados obtidos estão apresentados na tabela abaixo:

\begin{tabular}{|c|c|c|c|c|c|}
\hline Dimensão da célula unitária (m) & 4096 & 2048 & 1024 & 512 & 256 \\
\hline Número de células & 1 & 4 & 16 & 64 & 256 \\
\hline Número de poços produtores & 1 & 4 & 16 & 64 & 256 \\
\hline Número de poços injetores & 4 & 9 & 25 & 81 & 289 \\
\hline $\begin{array}{l}\text { VPL da receita de óleo por poço } \\
\text { produtor (milhões US\$) }\end{array}$ & 228,54 & 228,54 & 162,94 & 60,637 & 16,943 \\
\hline $\begin{array}{l}\text { VPL da receita de óleo total } \\
\text { (milhões US\$) }\end{array}$ & 228,54 & 914,18 & 2607,1 & 3880,8 & 4337,5 \\
\hline $\begin{array}{l}\text { Custo com poços produtores } \\
\text { (milhões US\$) }\end{array}$ & 40,000 & 160,00 & 640,00 & 2560,0 & 10240 \\
\hline $\begin{array}{l}\text { Custo com poços injetores } \\
\text { (milhões US\$) }\end{array}$ & 240,00 & 540,00 & 1500,0 & 4860,0 & 17340 \\
\hline $\begin{array}{l}\text { Custo total com poços (milhões } \\
\text { US\$) }\end{array}$ & 280,00 & 700,00 & 2140,0 & 7420,0 & 27580 \\
\hline Lucro total final (milhões US\$) & $-51,455$ & 214,18 & 467,05 & $-3539,2$ & -23242 \\
\hline
\end{tabular}


A primeira conclusão é que a configuração de maior lucro final é aquela que divide o reservatório em 16 células de injeção e produção five-spot, logo essa é a solução da otimização, com valor de US\$ 467,05 milhões. Entretanto, mais do que apenas obter um resultado, é importante para a tomada de decisões realizar uma análise de sensibilidade do problema, de modo a observar como a decisão pode ser influenciada pela oscilação de parâmetros de interesse.

\subsection{Análise de Sensibilidade}

A análise de sensibilidade [2] foi realizada em relação às variáveis receita unitária do barril de óleo no tempo zero, taxa de desconto nominal anual, custo unitário de um poço produtor e custo unitário de um poço injetor. A tabela a seguir mostra os ranges dessas variáveis para a análise:

\begin{tabular}{|l|l|l|l|}
\hline Variável & Limite inferior & Valor médio & Limite superior \\
\hline Receita do óleo ( dólares por barril ) & 20 & 50 & 80 \\
\hline Taxa de desconto anual nominal (\%) & 0 & 15 & 30 \\
\hline Custo do injetor ( milhões de dólares ) & 45 & 60 & 75 \\
\hline Custo do produtor ( milhões de dólares ) & 25 & 40 & 55 \\
\hline
\end{tabular}

Em primeiro lugar, foi observado o comportamento do lucro total de cada uma das 5 escolhas de divisão do reservatório, em 1, 4, 16, 64 ou 256 células five-spot, em função dos custos de poços injetores e produtores. Para cada uma dessas escolhas, é apresentado um gráfico a seguir, que mostra o lucro total final em função dos custos unitários de poços produtores e injetores, em milhões de dólares. Os parâmetros de receita unitária do óleo e taxa de desconto foram mantidos em seus valores médios.

Lucro total em função do custo unitário dos poços, para as 5 estratégias utilizadas.

Eixo horizontal - poço produtor.

Eixo vertical - poço injetor.

Valores em milhões de dólares.
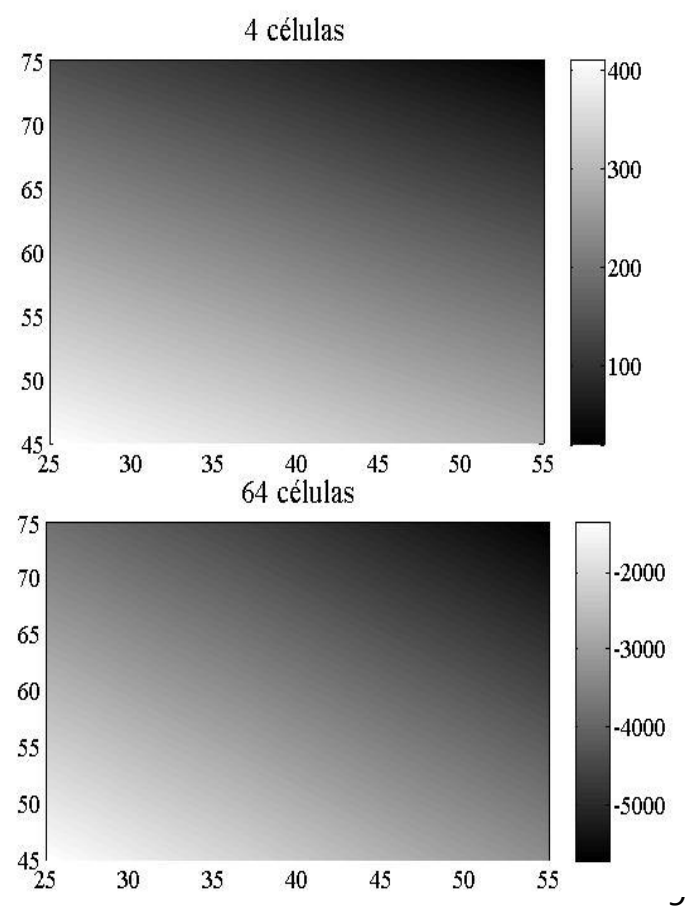

1 célula
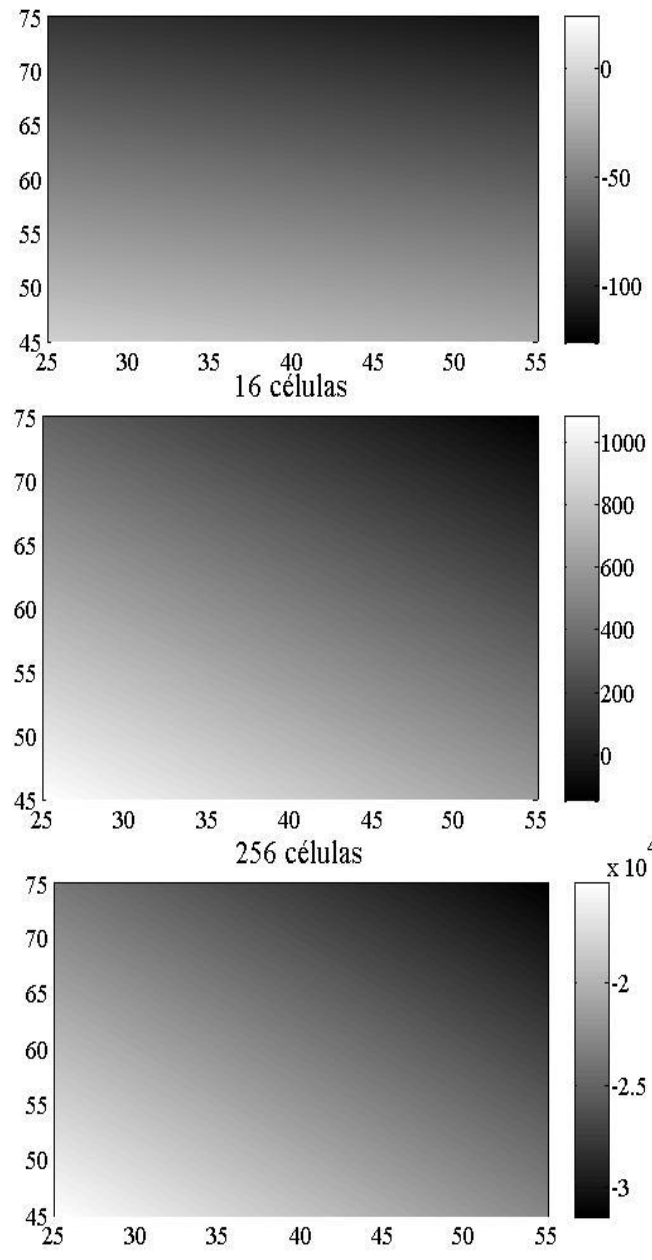
Em primeiro lugar, pode-se concluir que a escolha da estratégia de divisão do reservatório em 16 células five-spot é robusta em relação à análise de sensibilidade com os custos de poços, ou seja, continua constituindo a escolha ótima para a maior parte do domínio de valores envolvido na análise. Exceção se constitui quando os custos unitários de ambos os poços produtores e injetores aumentam muito, aproximando-se dos limites analisados, e então a estratégia da divisão em 4 células se torna mais atrativa. Isso é completamente compreensível, dado que o aumento no custo dos poços pode atingir nível tal que o ganho em produção da estratégia de 16 células em relação à de 4 células passe a não mais compensar o aumento no custo total com a instalação de mais poços.

Outra observação interessante refere-se a um comportamento melhor evidenciado pela seguinte forma de exibição dos mesmos dados:

Curvas de nível do lucro total em função do custo unitário dos poços, para as 5 estratégias utilizadas. Eixo horizontal - poço produtor.

Eixo vertical - poço injetor. Valores em milhões de dólares
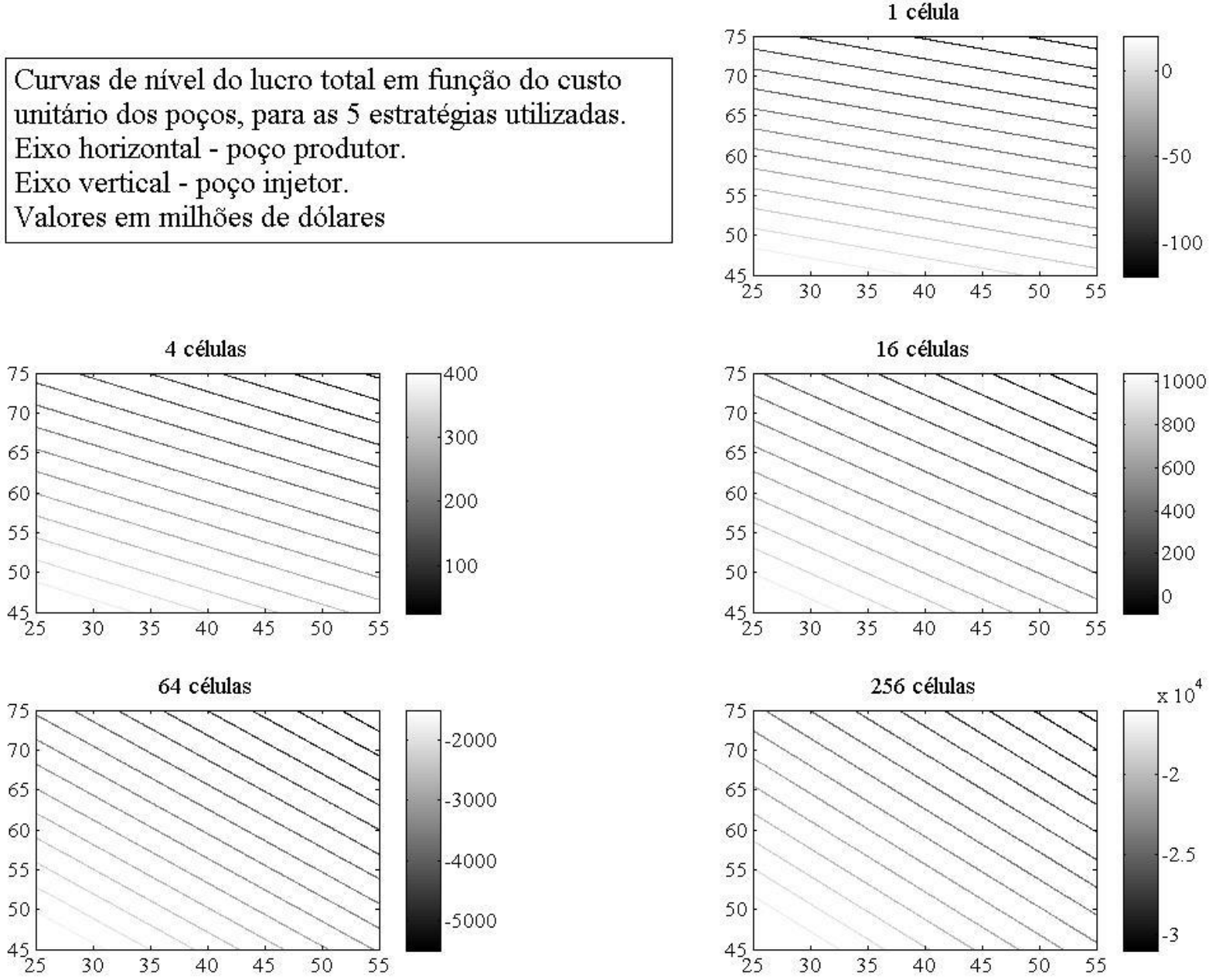

Pode-se observar que a inclinação das curvas de nível dos gráficos acima varia. As curvas são mais horizontais para a estratégia de 1 célula e mais inclinadas para a estratégia de 256 células. Isso ilustra algo que já se poderia esperar em relação à dependência do lucro total final pelos custos unitários dos poços: quanto maior o número de células unitárias, mais o número de poços produtores se aproxima do número de poços injetores, enquanto que a diferença relativa entre esses números é máxima para o caso de 1 célula. Isso pode ser sintetizado afirmando-se que a participação do custo com poços produtores em relação ao custo total cresce na medida em que o número de células five-spot utilizadas é maior, e depois converge para um valor proporcional aos custos unitários de poços produtores e injetores.

A segunda parte da análise de sensibilidade procurou observar a relação entre o lucro total e as variações na taxa de desconto nominal anual e na receita unitária do barril do petróleo no tempo zero. Essas relações podem ser observadas nos gráficos abaixo: 
Lucro total em função da receita unitária do barril de óleo no tempo zero e da taxa de desconto nominal anual.

Eixo horizontal - receita do barril, em dólares por barril.

Eixo vertical - taxa de desconto, em valor absoluto.
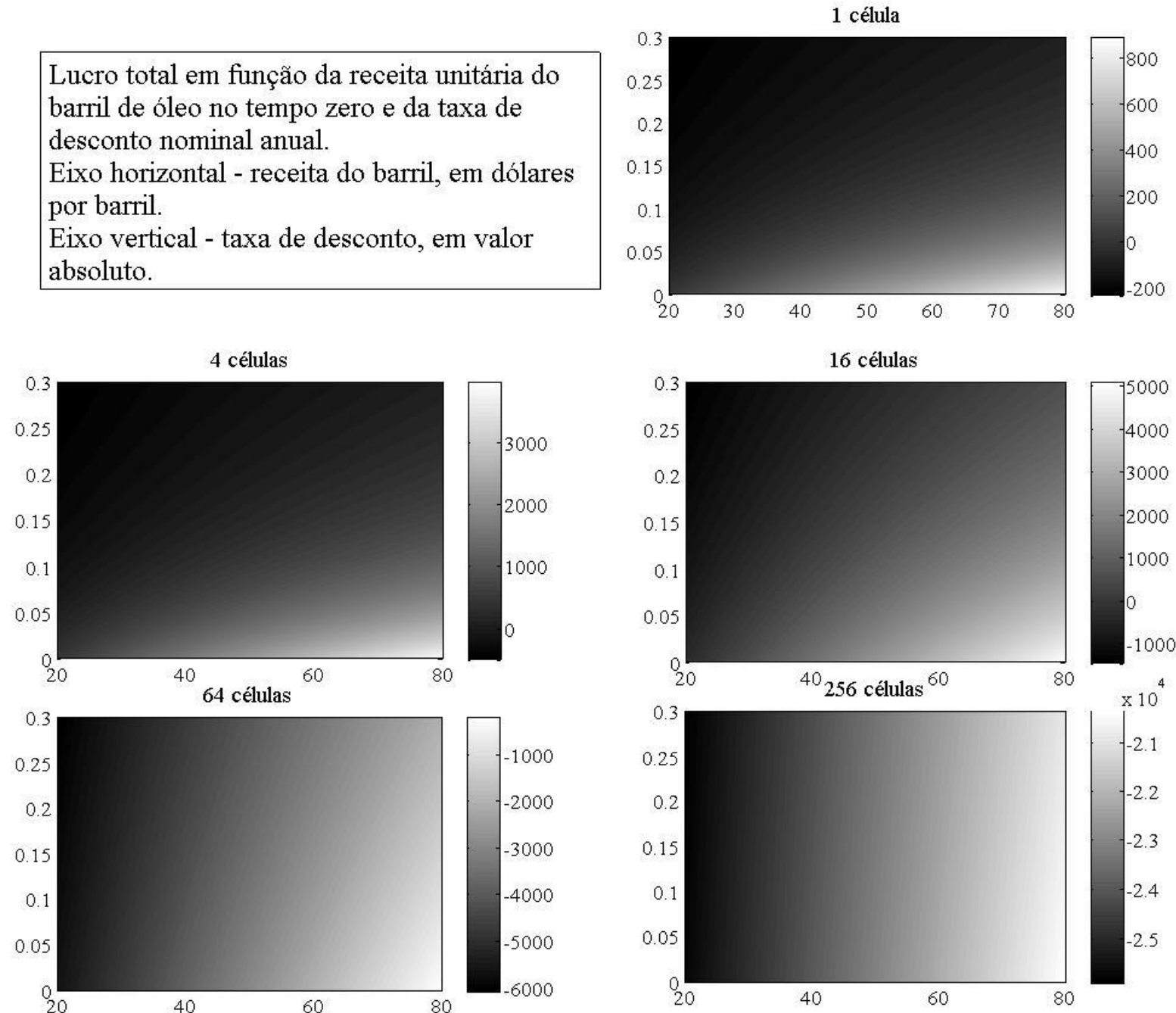

Pode-se notar que a sensibilidade do lucro total final a essas variáveis é maior que quando observamos a influência dos custos dos poços. Primeiro, a forma das curvas de nível varia desde o que parece ser uma função logarítmica para número baixo de células utilizadas até se transformar quase em uma reta vertical, que constitui o comportamento assintótico. Isso acontece porque, à medida que a quantidade de células aumenta, atinge-se mais rapidamente o limite de cut de água, consequentemente, no limite, a produção de óleo se dá toda no instante zero, de maneira que se torna insensível a flutuações na taxa de desconto.

Além disso, se considerarmos o domínio de valores da taxa de desconto e da receita unitária do óleo, tanto a estratégia de 4 células como a estratégia de 16 devem ser consideradas para a tomada de decisões em relação ao problema estudado. Isso acontece porque, dependendo dos desvios em relação aos valores médios das variáveis utilizados no problema de otimização, a estratégia do uso de 4 células pode ser melhor que a estratégia de 16 células. Pode-se entender rapidamente este fato observando que o melhor cenário para 16 células tem valor maior que o melhor cenário para 4 células, mas o pior cenário para 16 tem valor menor que o pior cenário para 4.

A menor amplitude de variações do valor do lucro total para a escolha de 4 células pode ser atrativa para um tomador de decisões conservador, visto que essa decisão maximiza o valor do pior cenário, quando comparada à escolha de 16 células. Com o mesmo raciocínio, observa-se que um tomador de decisão ousado decidiria pela estratégia de 16 células, já que esta maximiza o valor do cenário mais otimista, em relação à estratégia de 4 células. 
Dada a escolha de uma estratégia, é interessante a obtenção da curva da Taxa Interna de Retorno em função de variáveis do problema. A TIR é a taxa de desconto para a qual o Valor Presente Líquido do projeto é igual a zero, logo é um importante indicador para o projeto e uma boa base de comparação para projetos com tempo de vida diferentes, como neste caso. Considerando, em nosso caso, que o tomador de decisão escolheu a estratégia de 16 células, pode-se obter a seguinte curva da TIR:

\section{Taxa Interna de Retorno em função da receita unitária do óleo}

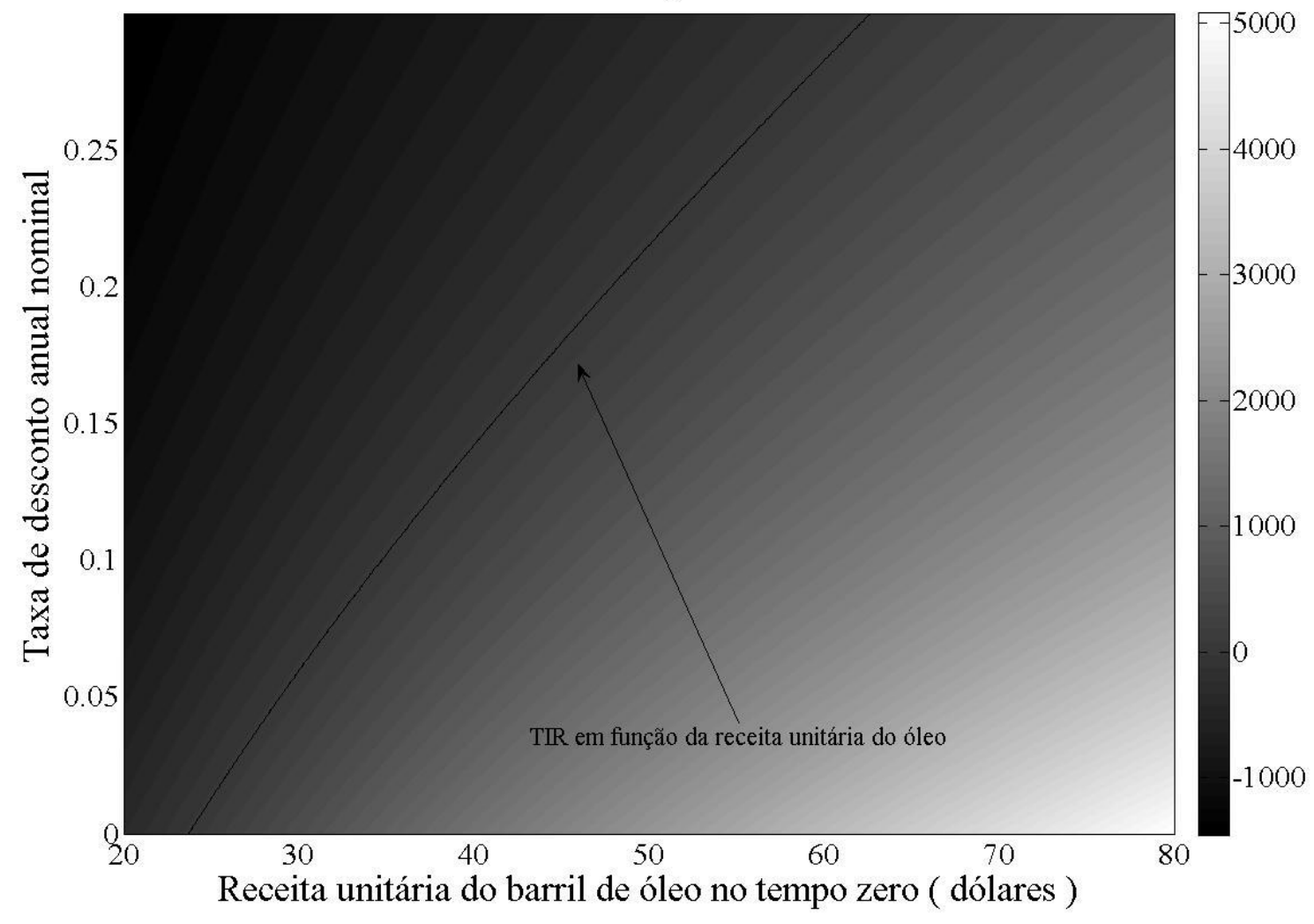

\section{CONCLUSÃO}

Com esse estudo, foi possível observar como a simulação numérica de reservatórios de petróleo e a análise de sensibilidade podem constituir ferramentas importantes para a tomada de decisão em relação à exploração de reservatórios de petróleo. Com a análise específica de reservatórios explorados por injeção de água em malhas five-spot, foi visto que é possível estabelecer uma formulação metódica para a realização de simulações de maneira inteligente e computacionalmente eficiente, lançando-se mão de um argumento geométrico e físico proveniente da engenharia de reservatórios de petróleo. $\mathrm{O}$ método de análise e tomada de decisão aqui estudado pode ser utilizado como primeira ferramenta para a análise de reservatórios mais complexos, servindo para restringir o domínio do problema antes que métodos mais custosos de estudo sejam empregados. Além disso, à análise de sensibilidade poder-se-ia adicionar uma análise da variância, tornando mais precisa a ideia de risco do projeto e mais clara a tomada de decisão.

\section{REFERÊNCIAS BIBLIOGRÁFICAS}

[1] Rosa, A. J.; Carvalho, R. S. \& Xavier, J. A. D: Engenharia de Reservatórios de Petróleo. Rio de Janeiro, Editora Interciência, 2006.

[2] Motta, R. R.; Análise de investimentos: tomada de decisões em projetos industriais. São Paulo: Atlas, 2002. 